\title{
Fat Embolism Syndrome - A Qualitative Review of its Incidence, Presentation, Pathogenesis and Management
}

\author{
Timon C, MCh, Keady C, MSC, Murphy CG, FRCS \\ Department of Trauma and Orthopaedics, Galway University Hospitals, Galway, Ireland

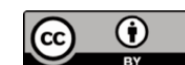 \\ This is an open-access article distributed under the terms of the Creative Commons Attribution License, which permits unrestricted use, \\ distribution, and reproduction in any medium, provided the original work is properly cited \\ Date of submission: 12th November 2020 \\ Date of acceptance: 05th March 2021
}

\begin{abstract}
Fat Embolism Syndrome (FES) is a poorly defined clinical phenomenon which has been attributed to fat emboli entering the circulation. It is common, and its clinical presentation may be either subtle or dramatic and life threatening. This is a review of the history, causes, pathophysiology, presentation, diagnosis and management of FES. FES mostly occurs secondary to orthopaedic trauma; it is less frequently associated with other traumatic and atraumatic conditions. There is no single test for diagnosing FES. Diagnosis of FES is often missed due to its subclinical presentation and/or confounding injuries in more severely injured patients. FES is most frequently diagnosed using the Gurd and Wilson criteria, like its rivals it is not clinically validated. Although FES is a multi-system condition, its effects in the lung, brain, cardiovascular system and skin cause most morbidity. FES is mostly a self-limiting condition and treatment is supportive in nature. Many treatments have been trialled, most notably corticosteroids and heparin, however no validated treatment has been established.
\end{abstract}

Keywords:

fat embolism syndrome, fat embolism, trauma, orthopaedics

\section{METHOD}

SRQR guidelines were employed to guarantee the transparency of this qualitative research. This formula defines a clear standard for reporting qualitative research while preserving the requisite flexibility to accommodate various paradigms, approaches and methods. This qualitative systematic review provides an up-to-date summary of the incidence, presentation, pathogenesis and management of Fat Embolism Syndrome.

\section{DEFINITION AND INTRODUCTION}

Fat embolism ${ }^{1}$ occurs when fat enters the circulation, this fat can embolise and may or may not produce clinical manifestations.

FES is a poorly defined clinical phenomenon which has been attributed to fat emboli entering the circulation. It classically presents with respiratory, neurological and dermatological features. It typically occurs after long-bone fractures and total hip arthroplasty, less frequently it is caused by burns and soft tissue injuries ${ }^{2}$. Early stabilisation of long bone fractures is thought to reduce its incidence, however the most effective means of achieving this has yet to be determined ${ }^{3}$. It is one of the least understood complications of trauma.

\section{EPIDEMIOLOGY AND INCIDENCE}

FES occurs most frequently following orthopaedic trauma; however, it has been documented in the literature as having occurred following other traumatic conditions such as burns, hepatic injury, cardiopulmonary resuscitation compressions, bone-marrow transplant, lung transplant, liposuction, caisson disease, extracorporeal circulation, tetrachloromethane poisoning, and caesarean section. Fat emulsion injection, corticosteroid therapy, pancreatitis, angiomyolipoma, intravenous lipid infusion, and haemoglobinopathies such as sickle cell disease (SCD) are rare non-traumatic causes of $\mathrm{FES}^{4-8}$.

Incidence of fat embolism and FES varies significantly throughout the literature depending on series design. Long-term retrospective review reports the lowest rates. Muller reported the incidence of fat embolism in long bone fractures is $0.9 \%$ to $2.2 \%$ of cases $^{9}$ and that during 
intramedullary manipulation/ instrumentation the incidence tends to be lower $(0.5-0.8 \%)$.

Prospective studies report far higher yet consistent rates of FES, while the incidence of FE at autopsy is significantly greater than the incidence of clinically suspected FES?.

FES occurring after cosmetic procedures such as liposuction and gluteal vitamin $\mathrm{E}$ injections is a well-described phenomenon that has even led to fatalities ${ }^{10,11}$. While these aesthetic procedures are relatively safe, clinicians should be aware of the possibility of FES in the postoperative period, and exercise suspicion should their patient become acutely unwell.

FES due to extensive bone marrow necrosis in Sickle Cell Disease (SCD) is also a rare but well-described complication with a mortality rate of $64 \%{ }^{12}$. Surprisingly, patients with the "milder" form of SCD seem to be most at risk, $81 \%$ of patients in a review article had a genotype other than HbSS.

\section{Incidence diagnosed by clinical criteria}

Gurd, in his 1974 paper reported the incidence of FES as $19 \%$ in a group of trauma patients 5 . In a 10 -year review carried out by a major American trauma centre an incidence of $0.9 \%$ was reported ${ }^{13}$. Interestingly, the authors found no correlation between the severity, location or pattern of patients' injuries and their likelihood of developing FES, contradicting other studies which have shown a significant association between "at-risk fractures" (fractures of the femur, tibial shaft or pelvis) and incidence of $\mathrm{FES}^{14}$. The same study also reported a correlation between the number of fracture sites and the incidence of FES.

\section{Incidence established by serial monitoring}

One trauma centre ran a prospective evaluation where they sought to determine the true incidence of FES following long bone or pelvic fracture. They identified patients with pulmonary shunts by measuring the alveolar/arterial PO2 gradient, and then subcategorised them further to establish a minimum incidence of FES. 49 out of 92 patients had a pulmonary shunt, 39 of them also had a pulmonary injury which was at least partially responsible for the shunt, leading them to conclude that at least 10 patients $(11 \%)$ had FES secondary to a long bone or pelvic fracture ${ }^{15}$.

\section{Incidence established by laboratory testing}

One series in an arthroplasty centre took serial arterial and right atrial blood samples for histopathology in patients undergoing both unilateral and simultaneous bilateral total knee arthroplasty (TKA). The researchers looked for fat cells at multiple time points and found an incidence of fat embolism of $46 \%$ in 100 patients with a unilateral TKA and $65 \%$ in 100 patients with bilateral $\mathrm{TKAs}^{16}$. Neurological manifestations consistent with FES were reported in two patients from the unilateral group and four patients from the bilateral group (Table I).

\section{PRESENTATION AND CLINICAL SEQUELAE}

FES is both a clinical diagnosis and a diagnosis of exclusion because it is often associated with concomitant injury/ illness. This also leads to difficulty in evaluating the severity of FES.

Signs and symptoms of FES usually present within 24-48 hours of trauma. FES classically presents with changes affecting the respiratory, neurological and dermatological systems.

FES may also present more severely with pulmonary and systemic embolisation of fat, right ventricular failure and cardiovascular collapse. Pell recounted a most dramatic case of fulminant FES that occurred intra-operatively, a patient suddenly developed cor pulmonale during open fixation of a femoral fracture, a patent foramen ovale was discovered at autopsy and a posthumous diagnosis of FES was made ${ }^{17}$.

\section{Respiratory}

Respiratory signs and symptoms are the most frequent presentation of FES. This can range from transient respiratory distress to fulminant respiratory failure. In Lindeque's study, 16 of 28 patients with lower limb long bone fractures had a $\mathrm{PaO} 2$ of less than $7.3 \mathrm{kPa}^{7}$, a similar study of polytrauma patients reported a $\mathrm{PaO} 2$ of less than $9.3 \mathrm{kPa}$ in $90 \%$ of included patients. Bulger conducted a $10-$ year study in a major trauma centre in an attempt to better define FES and diagnosed 27 patients with FES, 12 (44\%) required mechanical ventilation12. Diagnosis seems linked to the intensity of focus on signs or symptoms of the syndrome.

\section{Neurological}

Neurological sequelae are also common in FES and presentation can vary dramatically, from mild confusion to drowsiness to a comatose state. DeFroda published a case report of cerebral FES in 2016 of an otherwise healthy young woman presenting with devastating symptoms post reamed intramedullary nail fixation of a femoral fracture ${ }^{18}$. Rare cases of massive cerebral fat embolism leading to brain death are reported ${ }^{19}$. In 2015, a case report was published concerning a woman who died after developing nonconvulsive status epilepticus after undergoing total knee arthroplasty. She remained in refractory status epilepticus for two weeks before passing away. At autopsy multiple cerebral infarcts associated with fat emboli were found ${ }^{20}$. This was the first described case of this kind, yet another example of our lack of understanding of the pathophysiology of FES. Scopa described an atypical presentation of FES where neurological symptoms were present without respiratory symptoms ${ }^{21}$. Bulger found that neurological changes were present in $59 \%$ of patients ${ }^{13}$. Minor global dysfunction is the most common presentation but there have been dramatic cases of rapid onset hemiparesis, blindness and seizures. Fortunately, neurological symptoms of FES often resolve 
Table I: The incidence and mortality of fat embolism syndrome in recent and landmark series

\begin{tabular}{|c|c|c|c|c|}
\hline First Author & Year & Study Design & Incidence(n) & Mortality(n) \\
\hline \multicolumn{5}{|l|}{ Incidence from clinical series } \\
\hline Robert & 1993 & 25 years retrospective review & $0.26 \%(20)$ & $20 \%(4)$ \\
\hline Bulger EM & 1997 & 10-year review of trauma cases & $0.9 \%(27)$ & $7 \%(2)$ \\
\hline \multicolumn{5}{|l|}{ Data from prospective studies } \\
\hline Schonfeld & 1983 & $\begin{array}{l}\text { Randomised trial of corticosteroids } \\
\text { in prophylaxis of FES }\end{array}$ & $\begin{array}{l}15 \%(9) \\
\text { cumulatively }\end{array}$ & 0 \\
\hline Chan & 1984 & 80 consecutive trauma patients & $\begin{array}{l}8.5 \%(7) \\
35 \% \text { of patients } \\
\text { with multiple } \\
\text { injuries }\end{array}$ & $2.5 \%(2)$ \\
\hline Lindeque & 1987 & $\begin{array}{l}\text { Randomised trial of } \\
\text { methylprednisolone's efficacy }\end{array}$ & $\begin{array}{l}13 \%(7) \text { by } \\
\text { Gird criteria } \\
29 \%(16) \text { by own } \\
\text { criteria }\end{array}$ & 0 \\
\hline Kallenbach & 1987 & $\begin{array}{l}\text { Randomised trial of corticosteroids } \\
\text { as prophylaxis in } 84 \text { trauma patients }\end{array}$ & $\begin{array}{l}13 \%(11) \\
\text { cumulatively }\end{array}$ & Nil \\
\hline \multicolumn{5}{|l|}{$\begin{array}{l}\text { Laboratory testing of blood } \\
\text { samples }\end{array}$} \\
\hline Kim YH & 2001 & $\begin{array}{l}\text { Histological staining of arterial } \\
\text { and right-atrial blood from } \\
\text { intra-operative arthroplasty } \\
\text { patients for fat cells }\end{array}$ & $\begin{array}{l}65(65 \%) \\
\text { (Bilateral TKA) } \\
46(46 \%) \\
\text { (Unilateral TKA) }\end{array}$ & \\
\hline \multicolumn{5}{|l|}{ Incidence from TOE series } \\
\hline Pell & 1993 & $\begin{array}{l}\text { Study of } 24 \text { tibial and femoral } \\
\text { fractures }\end{array}$ & $\begin{array}{l}6(25 \%) \text { (Significant } \\
\text { showers small emboli) } \\
4(16.6 \%) \text { (Large emboli) } \\
3(12.5 \%) \text { FES }\end{array}$ & $1(4.1 \%)$ \\
\hline Christie & 1995 & $\begin{array}{l}111 \text { invasive intramedullary } \\
\text { procedures }\end{array}$ & 97 (87\%) (Emboli seen) & \\
\hline
\end{tabular}

Abbreviations: TKA: Total Knee Arthroplasty, FES: Fat embolism syndrome

Table II: Gurd and Wilson Criteria for FES ${ }^{3}$

\begin{tabular}{|l|}
\hline \multicolumn{2}{|c|}{ Two major criteria / one major criteria and four minor criteria suggest a diagnosis of FES } \\
Minor Criteria
\end{tabular}

Table III: Schonfeld's scoring system for diagnosing FES ${ }^{6}$

\section{Score $>5$ points diagnoses FES}

Sign/ Symptom:

- Petechial Rash (5 points)

- Diffuse infiltrates on chest x-ray chest (4)

- Fever (1)

- Tachycardia (1)

- Tachycardia (1)

- Confusion (1)
Table IV: Lindeque's Criteria for FES ${ }^{5}$

\begin{tabular}{l}
\hline Criteria: \\
\hline - $\mathrm{pO} 2<8 \mathrm{kpa}$ \\
- $\mathrm{pCO} 2>7.3 \mathrm{kpa}$ \\
- Respiratory rate $>35 / \mathrm{min}$; despite sedation \\
- Dyspnoea, tachycardia, anxiety \\
\hline
\end{tabular}


spontaneously without sequelae ${ }^{22}$. In patients with long bone fractures, who deteriorate neurologically without respiratory compromise, cerebral fat embolism should be suspected, except for those with intracranial lesions, as early diagnosis and comprehensive management can improve prognosis ${ }^{23}$. Magnetic resonance imaging is the imaging modality of choice for cerebral $\mathrm{FES}^{24}$.

\section{Dermatological}

A petechial rash is characteristic of FES. This rash typically can be seen on the head, neck, anterior thorax and axillae. Tachakra's hypothesis is that this pattern is caused by fat droplets aggregating in the aortic arch and then embolising to nondependent skin via the subclavian and carotid vessels 25 . Stasis, depletion of clotting factors, thrombocytopenia and damage to capillary endothelium from FFAs are all contributory causes of petechial rashes that occur in $\mathrm{FES}^{26}$.

\section{Retinal}

Ocular fat embolism syndrome in the absence of cardiac defects is rare but has been described in a case report. The author's hypothesis was that small fat droplets may pass through the lung capillaries or pre-capillary shunts and enter the systemic circulation ${ }^{27}$. Ocular FES is a separate entity to Purtscher's retinopathy which is associated with head/chest trauma or acute pancreatitis ${ }^{28}$.

\section{Laboratory Tests}

Laboratory Tests have been used in identifying FES, unfortunately they are non-specific and cannot be reliably used as FES nearly always occurs in the presence of multiple injuries/illness.

Unexplained anaemia occurs in $67 \%$ of patients with FES, thrombocytopenia is less prevalent, but still common ${ }^{13}$. The mechanism of this thrombocytopenia is still not understood, platelet consumption due to disseminated intravascular coagulation and platelet activation by bone marrow emboli with thrombus formation are two theories that Riseborough proposed and are yet to be usurped ${ }^{29}$.

Serum phospholipase A2 (sPLA2) is an important inflammatory mediator and liberates FFAs, which are responsible for acute lung injury in FES. Acute Chest Syndrome (ACS) is the leading cause of death in sickle cell disease, in severe ACS fat embolism is often present. It was shown that SPLA2 levels are dramatically elevated in patients with ACS and that levels even correlated with the severity of $\mathrm{ACS}^{30}$. Thus, it was proposed that SPLA2 levels could be used to diagnose FES in high-risk patients. Unfortunately, these elevated sPLA2 levels were shown to not be specific to FES and may just be a manifestation of altered lipid metabolism after trauma ${ }^{31}$.

Bronchoscopy and bronchoalveolar lavage (BAL) have also been investigated as means of diagnosing $\mathrm{FES}^{32-34}$.
Macrophages cells which clean up debris in the lungs at a cellular level could be expected to contain fat cells. Unfortunately, obtaining usable samples proved more difficult than initially thought. In one study 67 out of 96 samples were void due to low yield of macrophages ${ }^{35}$. Furthermore, the stain used to test for fat cells in these investigations (oil red $\mathrm{O}$ ), stains neutral fat, not FFAs i.e. the fat cells which do not cause acute lung injury ${ }^{36}$. Nevertheless, it is thought that the use of a threshold value (e.g. 30\%) of macrophages staining positive for fat could be useful in trauma patients, perhaps even to rule out FES and prompt investigations for an alternative source of hypoxaemia ${ }^{37}$.

\section{Radiology}

Imaging could play a role in FES when neurological involvement is suspected. In the acute setting computed tomography shows no abnormalities ${ }^{38}$, however magnetic resonance imaging (MRI) of the brain has been shown to be useful in early diagnosis of cerebral fat embolism, highintensity signals are visible in $\mathrm{T}_{2}$ weighted images as soon as four hours after symptoms onset. Furthermore, MRI images appear to correlate with the severity of symptoms and with resolution $^{39}$, making MRI as a useful potential tool for grading the severity of cerebral FES and its evolution/resolution.

Suzuki described the lesions as being characteristically along the boundary zones of the major vascular territories and suggested a link between the hypoxic brain condition in FES and the mechanical aggregation of fat globules and blockage of entire brain capillaries ${ }^{39}$. These characteristic findings can be useful for differentiating FES from primary intra-axial brain injury in patients with polytrauma ${ }^{40}$.

More recently an American systematic review was published that identified five distinctive MRI image patterns through the three phases of cerebral fat embolism ${ }^{41}$ : scattered cytotoxic oedema occurred in the acute stage, while confluent cytotoxic oedema or vasogenic oedema occurred in the subacute stage, in the long-term brain atrophy and demyelination was identified. Petechial haemorrhages in a confluent shape were seen in all stages of cerebral FES. Early recognition of these patterns may help identify the appropriate management.

In patients with respiratory compromise following trauma or an orthopaedic procedure, diffuse, well-demarcated ground glass opacities or ill-defined centrilobular nodules on computed tomography while non-specific, should give clinicians a cause for suspecting $\mathrm{FES}^{42}$. It is vital that radiologists, orthopaedic surgeons and clinicians are familiar with the clinical presentation and imaging of FES to allow for early diagnosis and adequate management. 


\section{DIAGNOSTIC CRITERIA}

Fat embolism is a pathological process where fat cells enter the circulation; thus, this phenomenon can only be demonstrated conclusively/empirically at autopsy. FES is the clinical manifestation of this process. There is no single laboratory or radiological test that can make a diagnosis of FES. Several criteria have been designed to diagnose FES. Gurd and Wilson criteria (Table II) is the most widespread of three criteria proposed to suggest a diagnosis of FES. Gurd proposed his original criteria in 1970 before modifying it with Wilson in $1974^{4,5}$. A common criticism of Gurd's criteria is that fat macroglobulinemia is often found in the blood of healthy volunteers and trauma patients with no other evidence of $\mathrm{FES}^{43}$.

Historically, Schoenfeld's (Table III) and Lindeque's criteria (Table IV) have also been used. Lindeque et al utilisation of their parameters on this led to a reported incidence of $29 \%$, higher than in any other comparable series. None of the above are clinically validated diagnostic criteria, nor are they accepted universally. Another criticism is that these criteria are overly broad and will capture many non-specific cases of respiratory failure, this may be responsible for the wide variability in the incidence noted in the prior section.

\section{PATHOPHYSIOLOGY}

The pathophysiology of FES remains unclear. The most widely accepted theories are approaching 100 years of age.

\section{Mechanical theory:}

In 1924 Gauss proposed that fat cells from the bone marrow could access venous sinusoids because of the increased intramedullary pressure that occurs following trauma ${ }^{44}$. These adipose cells have proinflammatory and prothrombotic attributes. As they traverse the venous system back towards the heart, they stimulate rapid platelet adhesion and increased fibrin generation, before eventually becoming stuck somewhere in the pulmonary arterial circulation as the vessels form capillaries. Capillary obstruction triggers interstitial haemorrhage, oedema, alveolar collapse and a reactive hypoxemic vasoconstriction. Massive fat emboli may also lead to macrovascular obstruction and shock ${ }^{45}$. Fat cells may enter the arterial circulation via a patent foramen ovale or directly through the pulmonary capillaries causing FES' characteristic dermatological and neurological findings $s^{46}$.

\section{Biochemical theory:}

Lehman hypothesised that the clinical manifestations of FES are caused by a proinflammatory state ${ }^{47}$. Adipose cells from bone marrow are broken down by tissue lipases forming glycerol and toxic free fatty acids (FFAs) e.g., chylomicrons causing injury to pneumocytes and pulmonary endothelial triggering a pro-inflammatory cytokine cascade which can culminate in Acute Respiratory Distress Syndrome. Lehman's theory may help to explain non-traumatic incidents of FES. Biochemical studies on animal models of FES support this theory.

The toxic properties of FFAs were first demonstrated in the 1950s by Peltier48. Since then FFA infusions have been used in animal-models to induce FES like changes in the circulation and lung ${ }^{49}$. There has been research using triolein, a FFA, to induce FES and investigate a "second hit" phenomenon in rat models. Lung damage following the injection of a pulmonary toxin was worse in rats who had a history of clinically resolved triolein-induced FES than in rats that were exposed to a pulmonary toxin alone ${ }^{50}$.

Aquaporins are cell membrane proteins that form pores in the membrane of biological cells ${ }^{51}$. The expression of an aquaporin called AQP1 was shown by Zhang et al to be increased in pulmonary oedema caused by FES $^{52}$. Furthermore, this occurred proportionally to the severity of pulmonary oedema. Zhang proposed that AQP1 could be regulated by FFAs, and therefore upregulated during FES, raising a potential opportunity to target $\mathrm{AQP} 1$ as a therapy for FES.

Oleic acid, the most abundant FFA in human adipose tissue ${ }^{53}$, is found in elevated levels in plasma and bronchoalveolar lavage fluids of patients with $\mathrm{ARDS}^{54}$. In animal models, it has been shown to provoke alveolar oedema, formation and prevent resolution, thereby contributing to the formation of $\mathrm{ARDS}^{54}$. Human albumin has multiple binding sites for FFAs $^{55}$. Stemming from this is the theory that hypoalbuminemia is a predisposing factor for FES in trauma $^{56}$, and it contributes towards an increased mortality risk in hospitalised patients ${ }^{57}$.

There is no clear evidence for the superiority of colloids over isotonic crystalloids in fluid resuscitation, and crystalloid resuscitation has been associated with a lower mortality rate in trauma patients, although the data from this study was not powered enough to influence clinical recommendations ${ }^{58}$. There is divergent data to suggest that, specifically, in the development of ARDS, fluid resuscitation with albumin solutions may be beneficial, because the oleic acid will bind to albumin reducing its potential to induce oedema ${ }^{59-61}$. Furthermore, the use of albumin when combined with furosemide in patients with ARDS tends to improve oxygenation and may reduce length of ventilation 60 .

\section{MANAGEMENT}

\section{Pharmacological modalities}

Currently there is no specific treatment for FES. A recent animal study showed that aliskiren, the renin inhibitor, protected the lungs of rats from gross and histopathologic damage after FE was induced by injecting fat 
intravenously ${ }^{62}$. Further studies are needed to see whether aliskiren could be used both, prophylactically before certain orthopaedic operations, and therapeutically after severe trauma to prevent the respiratory consequences of FES. A similar animal study was carried out using losartan on triolein-induced rat models of $\mathrm{FES}^{63}$. This study showed us that losartan helped protect the pulmonary system from chronic damage after FES. It also protected the rats from the second phenomenon as mentioned above. Both studies support the possibility of exploiting the renin-angiotensin system in the treatment of FES. Management of FES is often complicated by concomitant injuries and illnesses.

In the mid-20th century treatments such as heparin and dextran were trialled but neither yielded evidence of an improvement in morbidity or mortality ${ }^{64,65}$. As there is no specific treatment for FES, its management if focused on supportive care, symptom control and most importantly prevention.

\section{Philosophies of Orthopaedic Trauma}

Use of corticosteroids in FES prevention is controversial; although, there is evidence that corticosteroids can be used prophylactically to prevent FES in high-risk patients e.g. those who have suffered long-bone fractures ${ }^{8,66}$. However, a 2009 meta-analysis showed that while they did reduce rates of FES and hypoxia, corticosteroids did not reduce mortality rates $^{67}$, and the authors concluded that a larger randomised trial is needed. These studies cannot be applied to modern trauma populations given the ongoing debate about the timing of surgery for long bone fracture has evolved only recently to reach a consensus between Early Total Care and Damage Control Orthopaedics, an approach termed Early Appropriate Care ${ }^{68}$. Furthermore, none of these randomised controlled trials investigated the long-term complications of steroid treatment. Ultimately, a large confirmatory randomised-controlled trial will be needed to allow best practise of evidence-based medicine.

Even though fixation of long bone fractures is the most common cause of FES, prompt and adequate immobilisation of fractures may be very important in preventing the release of further adipose cells into the circulation ${ }^{69}$. Tanton proposed that proper immobilisation of a fracture may help reduce the rates of FES as far back as $1914^{70}$. A large Finnish trauma centre noticed a trend in decreased rates of FES following a change in policy to fix long bone fractures in the first days after injury ${ }^{71}$. A prospective American study showed that long bone fracture fixation within 24 hours reduced rates of FES, as well as ARDS and pneumonia in patients fit enough for surgery ${ }^{72}$. In fact, delayed fracture fixation has been shown to lead to longer ICU admissions ${ }^{73}$. Pape's 10-year retrospective study reported that early fracture fixation of a patient with co-existing chest injury led to increased incidence of $\mathrm{FES}^{69}$, therefore he proposed that patients with chest injuries should undergo un-reamed intramedullary nailing. This contradicts Brundage's findings, who concluded that delay of fixation surgery in patients with polytrauma was shown to lead to increased rates of FES as well as other complications and concluded that polytrauma is not a contraindication to early fixation ${ }^{74}$, Pinney et al also shared similar findings ${ }^{75}$.

\section{Fat Embolism During Intramedullary Nailing}

The systemic effects of intramedullary nailing were first described by Kuntscher ${ }^{76}$. Increased IM pressure has been shown to cause increased fat embolisation in vitro ${ }^{77}$. Richards found that reamed intramedullary nails were a risk factor for cognitive impairment one year post-operatively ${ }^{78}$. Applying a vacuum or venting during reaming has been shown to lessen intra-medullary pressure and therefore reduce fat embolisation ${ }^{78}$. Volgas monitored intracardiac fatty emboli with intraoperative transoesophageal echocardiography, comparing standard sequential reaming technique with a Reamer Irrigator-Aspirator system. He showed significantly lower levels of fatty emboli in the RIA group ${ }^{79}$. Unfortunately, the significant cost and bulkiness of the RIA system could hinder its widespread adoption. Baig describes the use of a technique which could be used with conventional reaming equipment where the suction tubing for intramedullary reaming is advanced to the end of IM bone and suction is applied for two to three minutes once access to the medullary canal is gained, the procedure is then carried out and suction repeated in a similar manner afterward $^{80}$. Medullary cavity irrigation has also been shown to lead to reduced emboli size on transoesophageal echocardiography during TKA ${ }^{81}$.

Muller compared intramedullary pressure across different reamer systems and found that decreasing the diameter of the flexible driver from $9 \mathrm{~mm}$ to $7 \mathrm{~mm}$ significantly reduced pressures. He also reported that using a $9.5 \mathrm{~mm}$ hollow reamer with a $7 \mathrm{~mm}$ diameter driver reduced operative intramedullary pressures by $61 \%$ to $66 \%{ }^{82}$.

In conclusion advances in technique and technology for commonly used reamer systems has facilitated the more aggressive fixation of fractures with reduced likelihood of fat embolisation and the development of FES.

\section{Management of Concomitant Lung Injuries}

ARDS leading to respiratory failure and even death is the most serious potential complication of FES. Management of ARDS secondary to FES aims to maintain adequate gas exchange while minimising the potential for ventilatorassociated lung injury (VALI). Enhancement of spontaneous breathing and coughing, early mobilisation, positive endexpiratory pressure (PEEP) and reduced sedation and neuromuscular blockade are some of the supportive therapies used to achieve this ${ }^{83}$. It is also important to consider the overlap of the immunological conditions associated with trauma, and how the impact of FES has not yet been clearly defined within this debate ${ }^{84}$. 
Care of patients with FES and neurological complications focuses on frequent neurological observations. Patients with FES may develop cerebral oedema, while this often resolves it sometimes causes severe morbidity ${ }^{85}$. In such cases intracranial pressure monitoring should be considered ${ }^{86}$. While clinical diagnosis is still seen as the preferable diagnostic method for $\mathrm{FES}^{87}$, studies have shown that MRI is useful, in cases where head trauma is not present in evaluating the severity of cerebral fat embolism and predicting long-term outcomes ${ }^{24}$. In general, sedation and neuromuscular blockade for trauma patients must be titrated so that the patient is kept comfortable, without affecting their serial neurological examinations and, also allowing them to tolerate mechanical ventilation $^{88}$.

\section{SUMMARY}

FES is a poorly defined clinical phenomenon which occurs because of fat emboli entering the circulation. FES mostly occurs secondary to orthopaedic trauma; it is less frequently associated with other traumatic and atraumatic conditions.
There is no single test that can be used to diagnose FES. Diagnosis of FES is often missed due to its subclinical presentation or confounding injuries in more severely injured patients. With supportive care the mortality rate is less than $10 \%$, and generally the complete resolution of pulmonary, neurological and dermatological symptoms. While prevention and excellent supportive care are the core tenets of its management, a high suspicion for FES in vulnerable patient cohorts, and early diagnosis leads to better prognosis. A better understanding of the role of the still research-based 'targeted' pharmacological therapies, coupled with advances in both the perioperative care of polytraumatised patients and the intra-operative techniques will all help reduce the impact of this condition. Similarly, clearer focus of the impact of FES on the immunomodulation of lung injury will help guide treatment.

\section{CONFLICTS OF INTEREST}

The authors declare no potential conflicts of interest.

\section{REFERENCES}

1. Kosova E, Bergmark B, Piazza G. Fat embolism syndrome. Circulation. 2015; 131(3): 317-20. doi: 10.1161/CIRCULATIONAHA.114.010835

2. Maitre S. Causes, clinical manifestations, and treatment of fat embolism. Virtual Mentor. 2006; 8(9): 590-2. doi: 10.1001/virtualmentor.2006.8.9.cprl1-0609

3. White T, Petrisor BA, Bhandari M. Prevention of fat embolism syndrome. Injury. 2006; 37(Suppl 4): S59-67. doi: 10.1016/j.injury.2006.08.041

4. Gurd AR. Fat embolism: an aid to diagnosis. J Bone Joint Surg Br. 1970; 52(4): 732-7.

5. Gurd AR, Wilson RI. The fat embolism syndrome. J Bone Joint Surg Br. 1974; 56B(3): 408-16.

6. Kwiatt ME, Seamon MJ. Fat embolism syndrome. Int J Crit Illn Inj Sci. 2013; 3(1): 64-8. doi: 10.4103/2229-5151.109426

7. Lindeque BG, Schoeman HS, Dommisse GF, Boeyens MC, Vlok AL. Fat embolism and the fat embolism syndrome. A doubleblind therapeutic study. J Bone Joint Surg Br. 1987; 69(1): 128-31. doi: 10.1302/0301-620X.69B1.3818718

8. Schonfeld SA, Ploysongsang Y, DiLisio R, Crissman JD, Miller E, Hammerschmidt DE, et al. Fat embolism prophylaxis with corticosteroids. A prospective study in high-risk patients. Ann Intern Med. 1983; 99(4): 438-43. doi: 10.7326/0003-4819-99-4-438

9. Muller C, Rahn BA, Pfister U, Meinig RP. The incidence, pathogenesis, diagnosis, and treatment of fat embolism. Orthop Rev. 1994;23(2):107-17.

10. Laub DR, Jr., Laub DR. Fat embolism syndrome after liposuction: a case report and review of the literature. Ann Plast Surg. 1990; 25(1): 48-52. doi: 10.1097/00000637-199007000-00011

11. Mendoza-Morales R, Camberos-Nava E, Luna-Rosas A, Garcés-Ramírez L, De la Cruz F, García-Dolores F. A fatal case of systemic fat embolism resulting from gluteal injections of vitamin e for cosmetic enhancement. Forensic Sci Intl. 2016; 259: e14. doi: 10.1016/j.forsciint.2015.11.012

12. Tsitsikas DA, Gallinella G, Patel S, Seligman H, Greaves P, Amos RJ. Bone marrow necrosis and fat embolism syndrome in sickle cell disease: increased susceptibility of patients with non-SS genotypes and a possible association with human parvovirus B19 infection. Blood Rev. 2014; 28(1): 23-30. doi: 10.1016/j.blre.2013.12.002 
13. Bulger EM, Smith DG, Maier RV, Jurkovich GJ. Fat embolism syndrome. A 10-year review. Arch Surg. 1997; 132(4): 435-9. doi: 10.1001/archsurg.1997.01430280109019

14. Robert JH, Hoffmeyer P, Broquet PE, Cerutti P, Vasey H. Fat embolism syndrome. Orthop Rev. 1993; 22(5): 567-71.

15. Fabian TC, Hoots AV, Stanford DS, Patterson CR, Mangiante EC. Fat embolism syndrome: prospective evaluation in 92 fracture patients. Crit Care Med. 1990; 18(1): 42-6.

16. Kim YH. Incidence of fat embolism syndrome after cemented or cementless bilateral simultaneous and unilateral total knee arthroplasty. J Arthroplasty. 2001; 16(6): 730-9. doi: 10.1054/arth.2001.23723.

17. Pell AC, Hughes D, Keating J, Christie J, Busuttil A, Sutherland GR. Brief report: fulminating fat embolism syndrome caused by paradoxical embolism through a patent foramen ovale. $N$ Engl J Med. 1993; 329(13): 926-9. doi: 10.1056/NEJM199309233291305

18. DeFroda SF, Klinge SA. Fat Embolism Syndrome With Cerebral Fat Embolism Associated With Long-Bone Fracture. Am $J$ Orthop (Belle Mead NJ). 2016; 45(7): E515-E21.

19. Hayes I, Walshe C, Kossmann T, Iles L, Cooper J. Cerebral fat embolism syndrome causing brain death after long bone fractures and acetazolamide therapy. Crit Care Resusc. 2007; 9(2): 184.

20. Fernandez-Torre JL, Burgueno P, Ballesteros MA, Hernandez-Hernandez MA, Villagra-Teran N, de Lucas EM. Super-refractory nonconvulsive status epilepticus secondary to fat embolism: A clinical, electrophysiological, and pathological study. Epilepsy Behav. 2015; 49: 184-8. doi: 10.1016/j.yebeh.2015.04.045

21. Scopa M, Magatti M, Rossitto P. Neurologic symptoms in fat embolism syndrome: case report. J Trauma. 1994; 36(6): 906-8. doi: 10.1097/00005373-199406000-00030

22. Jacobson DM, Terrence CF, Reinmuth OM. The neurologic manifestations of fat embolism. Neurology. 1986; 36(6): 847-51. doi: 10.1212/wnl.36.6.847

23. Shaikh N. Emergency management of fat embolism syndrome. J Emerg Trauma Shock. 2009; 2(1): 29-33. doi: 10.4103/09742700.44680

24. Parizel PM, Demey HE, Veeckmans G, Verstreken F, Cras P, Jorens PG, et al. Early diagnosis of cerebral fat embolism syndrome by diffusion-weighted MRI (starfield pattern). Stroke. 2001; 32(12): 2942-4.

25. Tachakra SS. Distribution of skin petechiae in fat embolism rash. Lancet. 1976; 1(7954): 284-5. doi: 10.1016/s01406736(76)91408-2

26. Jaffe FA. Petechial Hemorrhages A Review of Pathogenesis. Am J Forensic Med Pathol. 1994; 15(3): 203-7. doi: 10.1097/00000433-199409000-00004

27. Nentwich MM, Remy M, Schaller UC. Ocular fat embolism syndrome. Int Ophthalmol. 2011; 31(1): 15-6. doi: 10.1107/s10792010-9378-8

28. Agrawal A, McKibbin MA. Purtscher's and Purtscher-like retinopathies: a review. Surv Ophthalmol. 2006; 51(2): 129-36. doi: 10.1016/j.survophthal.2005.12.003

29. Riseborough EJ, Herndon JH. Alterations in pulmonary function, coagulation and fat metabolism in patients with fractures of the lower limbs. Clin Orthop Relat Res. 1976; (115): 248-67.

30. Styles LA, Schalkwijk CG, Aarsman AJ, Vichinsky EP, Lubin BH, Kuypers FA. Phospholipase A2 levels in acute chest syndrome of sickle cell disease. Blood. 1996; 87(6): 2573-8.

31. Ross AP. The value of serum lipase estimations in the fat embolism syndrome. Surgery. 1969; 65(2): 271-3.

32. Chastre J, Fagon JY, Soler P, Fichelle A, Dombret MC, Huten D, et al. Bronchoalveolar lavage for rapid diagnosis of the fat embolism syndrome in trauma patients. Ann Intern Med. 1990; 113(8): 583-8. doi: 10.7326/003-4819-113-8-583

33. Godeau B, Schaeffer A, Bachir D, Fleury-Feith J, Galacteros F, Verra F, et al. Bronchoalveolar lavage in adult sickle cell patients with acute chest syndrome: value for diagnostic assessment of fat embolism. Am J Respir Crit Care Med. 1996; 153(5): 1691-6. doi: 10.1164/ajrccm.153.5.8630622

34. Mimoz O, Edouard A, Beydon L, Quillard J, Verra F, Fleury J, et al. Contribution of bronchoalveolar lavage to the diagnosis of posttraumatic pulmonary fat embolism. Intensive Care Med. 1995; 21(12): 973-80. doi: 10.1007/BF01700658 
35. Vedrinne JM, Guillaume C, Gagnieu MC, Gratadour P, Fleuret C, Motin J. Bronchoalveolar lavage in trauma patients for diagnosis of fat embolism syndrome. Chest. 1992; 102(5): 1323-7. doi: 10.1378/chest.102.5.1323

36. Jones JG, Minty BD, Beeley JM, Royston D, Crow J, Grossman RF. Pulmonary epithelial permeability is immediately increased after embolisation with oleic acid but not with neutral fat. Thorax. 1982; 37(3): 169-74. doi: 10.1136/thx.37.3.169

37. Roger N, Xaubet A, Agusti C, Zabala E, Ballester E, Torres A, et al. Role of bronchoalveolar lavage in the diagnosis of fat embolism syndrome. Eur Respir J. 1995; 8(8): 1275-80. doi: 10.1183/09031936.95.08081275

38. Erdem E, Namer IJ, Saribas O, Aras T, Tan E, Bekdik C, et al. Cerebral fat embolism studied with MRI and SPECT. Neuroradiology. 1993;35(3):199-201. doi: 10.1007/BF00588493

39. Takahashi M, Suzuki R, Osakabe Y, Asai JI, Miyo T, Nagashima G, et al. Magnetic resonance imaging findings in cerebral fat embolism: correlation with clinical manifestations. J Trauma. 1999; 46(2): 324-7. doi: 10.1097/00005373-199902000-00021

40. Suzuki S, Hayashi T, Ri K, Hashimoto T, Matsui S, Kitanosono T, et al. Brain CT and MRI findings in fat embolism syndrome. Nihon Igaku Hoshasen Gakkai Zasshi. 1996; 56(6): 390-8.

41. Kuo KH, Pan YJ, Lai YJ, Cheung WK, Chang FC, Jarosz J. Dynamic MR imaging patterns of cerebral fat embolism: a systematic review with illustrative cases. AJNR Am J Neuroradiol. 2014; 35(6): 1052-7. doi: 10.3174/ajnr.A3605

42. Newbigin K, Souza CA, Torres C, Marchiori E, Gupta A, Inacio J, et al. Fat embolism syndrome: State-of-the-art review focused on pulmonary imaging findings. Respir Med. 2016;113:93-100. doi: 10.1016/j.rmed.2016.01.018

43. Nolte WJ, Olofsson T, Schersten T, Lewis DH. Evaluation of the Gurd test for fat embolism. J Bone Joint Surg Br. 1974; 56B(3): 417-20.

44. Gauss H. The pathology of fat embolism. Arch Surg. 1924; 9(3): 593-605. doi: 10.1001/archsurg.1924.01120090110007

45. Husebye EE, Lyberg T, Roise O. Bone marrow fat in the circulation: clinical entities and pathophysiological mechanisms. Injury. 2006; 37(Suppl 4): S8-18. doi: 10.1016/injury.2006.08.036.

46. Pell AC, Christie J, Keating JF, Sutherland GR. The detection of fat embolism by transoesophageal echocardiography during reamed intramedullary nailing. A study of 24 patients with femoral and tibial fractures. J Bone Joint Surg Br. 1993; 75(6): 9215. doi: 10.1302/0301-620X.75B6.8245083

47. Lehman EP, Moore RM. Fat embolism: including experimental production without trauma. Arch Surg. 1927; 14(3): 621-62. doi: 10.1001/archsurg.1927.01130150002001

48. Peltier LF. Fat embolism. III. The toxic properties of neutral fat and free fatty acids. Surgery. 1956; 40: 665-70.

49. Liu DD, Hsieh NK, Chen HI. Histopathological and biochemical changes following fat embolism with administration of corn oil micelles: a new animal model for fat embolism syndrome. J Bone Joint Surg Br. 2008; 90(11): 1517-21. doi: 10.1302/0301620X.90B11.20761

50. Poisner A, Herndon B, Lankachandra K, Likhitsup A, Al Hariri A, Kesh S, et al. Fat embolism sensitizes rats to a "second hit" with lipopolysaccharide: An animal model of pulmonary fibrosis. J Trauma Acute Care Surg. 2015; 78(3): 552-7. doi: 10.1097/TA.0000000000000539

51. Agre P. The aquaporin water channels. Proc Am Thorac Soc. 2006; 3(1): 5-13. doi: 10.1513/pats.200510-109JH

52. Zhang Y, Tian K, Wang Y, Zhang R, Shang J, Jiang W, et al. The Effects of Aquaporin-1 in Pulmonary Edema Induced by Fat Embolism Syndrome. Int J Mol Sci. 2016; 17(7): 1183 doi: 10.3390/ijms17071183

53. Kokatnur MG, Oalmann MC, Johnson WD, Malcom GT, Strong JP. Fatty acid composition of human adipose tissue from two anatomical sites in a biracial community. Am J Clin Nutr. 1979; 32(11): 2198-205. doi: 10.1093/acjn/32.11.2198

54. Vadasz I, Morty RE, Kohstall MG, Olschewski A, Grimminger F, Seeger W, et al. Oleic acid inhibits alveolar fluid reabsorption: a role in acute respiratory distress syndrome? Am J Respir Crit Care Med. 2005; 171(5): 469-79. doi: 10.1164/rccm.200407$9540 \mathrm{C}$

55. Goodman DS. The interaction of human serum albumin with long-chain fatty acid anions. J Am Chem Soc. 1958; 80(15): 38928. doi: 10.1021/ja01548a024

56. Moylan JA, Birnbaum M, Katz A, Everson MA. Fat emboli syndrome. J Trauma. 1976; 16(5): 341-7. doi: 10.1097/00005373197605000-00002 
57. Mogensen KM, Robinson MK, Casey JD, Gunasekera NS, Moromizato T, Rawn JD, et al. Nutritional Status and Mortality in the Critically Ill. Crit Care Med. 2015; 43(12): 2605-15. doi: 10.1097/CCM.0000000000001306

58. Perel P, Roberts I. Colloids versus crystalloids for fluid resuscitation in critically ill patients. Cochrane Database Syst Rev. 2012; (6): CD000567. doi: 10.1002/14651858.CD000567.pub6

59. Amanullah S, Venkataraman R. The routine use of albumin for fluid resuscitation of critically ill patients is not warranted. Crit Care. 2004; 8: E2. doi: 10.1186/cc3006

60. Calfee CS, Matthay MA. Nonventilatory treatments for acute lung injury and ARDS. Chest. 2007; 131(3): 913-20. doi: 10.1378/chest.06-1743

61. Uhlig C, Silva PL, Deckert S, Schmitt J, de Abreu MG. Albumin versus crystalloid solutions in patients with the acute respiratory distress syndrome: a systematic review and meta-analysis. Crit Care. 2014; 18(1): R10. doi: 10.1186/cc13187

62. Fletcher AN, Molteni A, Ponnapureddy R, Patel C, Pluym M, Poisner AM. The renin inhibitor aliskiren protects rat lungs from the histopathologic effects of fat embolism. J Trauma Acute Care Surg. 2017; 82(2): 338-44. doi: 10.1097/TA.0000000000001278

63. Poisner A, Herndon B, Bass D, Jain A, Fletcher A, Molteni A. Losartan protects the lung from chronic cellular damage induced by fat embolism (LB512). The FASEB Journal. 2014; 28(1): LB512. doi: 10.1096/fasebj.28.1_supplement.lb512

64. Lewis A, Pappas Am. Experimental fat embolism: evaluation of treatment with low molecular weight dextran. J Trauma Acute Care Surg. 1969; 9(1): 49-55.

65. Sage R, Tudor R. Treatment of fat embolism with heparin. British Med J. 1958; 1(5080): 1160. doi: 10.1136/bmj.1.5080.1160

66. Kallenbach J, Lewis M, Zaltzman M, Feldman C, Orford A, Zwi S. 'Low-dose' corticosteroid prophylaxis against fat embolism. J Trauma. 1987; 27(10): 1173-6.

67. Bederman SS, Bhandari M, McKee MD, Schemitsch EH. Do corticosteroids reduce the risk of fat embolism syndrome in patients with long-bone fractures? A meta-analysis. Can J Surg. 2009; 52(5): 386-93.

68. Tasker A, Kelly M. Managing trauma: the evolution from 'early total care'/‘damage control'to 'early appropriate care'. JTO. 2014; 2(2): 66-70.

69. Pape HC. Effects of changing strategies of fracture fixation on immunologic changes and systemic complications after multiple trauma: damage control orthopedic surgery. J Orthop Res. 2008; 26(11): 1478-84. doi: 10.1002/jor.20697

70. Tanton J. L'embolie graisseuse traumatique. J de Chir. 1914; 12: 287-96.

71. Riska EB, von Bonsdorff H, Hakkinen S, Jaroma H, Kiviluoto O, Paavilainen T. Prevention of fat embolism by early internal fixation of fractures in patients with multiple injuries. Injury. 1976; 8(2): 110-6. doi: 10.1016/0020-1383(76)-90043-7

72. Bone LB, Johnson KD, Weigelt J, Scheinberg R. Early versus delayed stabilization of femoral fractures. A prospective randomized study. J Bone Joint Surg Am. 1989; 71(3): 336-40.

73. Behrman SW, Fabian TC, Kudsk KA, Taylor JC. Improved outcome with femur fractures: early vs. delayed fixation. $J$ Trauma. 1990; 30(7): 792-7. doi: 10.1097/00005373-199007000-00005

74. Brundage SI, McGhan R, Jurkovich GJ, Mack CD, Maier RV. Timing of femur fracture fixation: effect on outcome in patients with thoracic and head injuries. J Trauma. 2002; 52(2): 299-307. doi: 10.1097/00005373-200202000-00016

75. Pinney SJ, Keating JF, Meek RN. Fat embolism syndrome in isolated femoral fractures: does timing of nailing influence incidence? Injury. 1998; 29(2): 131-3. doi: 10.1016/s0020-1383(97)00154-x

76. Bick EM. The intramedullary Nailing of Fractures by G. Kuntscher. Translation of article in Archiv fur Klinische Chirurgie, 200:443,1940. Clin Orthop Relat Res. 1968; 60: 5-12.

77. Kropfl A, Berger U, Neureiter H, Hertz H, Schlag G. Intramedullary pressure and bone marrow fat intravasation in unreamed femoral nailing. J Trauma. 1997; 42(5): 946-54. doi: 10.1097/00005373-199705000-00028

78. Pitto RP, Koessler M, Kuehle JW. Comparison of fixation of the femoral component without cement and fixation with use of a bone-vacuum cementing technique for the prevention of fat embolism during total hip arthroplasty. A prospective, randomized clinical trial. J Bone Joint Surg Am. 1999; 81(6): 831-43. doi: 10.2106/00004623-199906000-00010 
79. Volgas DA, Burch T, Stannard JP, Ellis T, Bilotta J, Alonso JE. Fat embolus in femur fractures: a comparison of two reaming systems. Injury. 2010; 41(Suppl 2): S90-3. doi: 10.1016/S0020-1383(10)70017-6

80. Baig MN, Curtin W. A Simple and Easy Intramedullary Lavage Method to Prevent Embolism During and After Reamed Long Bone Nailing. Cureus. 2017; 9(8): e1609. doi: 10.7759.cures.1609

81. Zhao J, Zhang J, Ji X, Li X, Qian Q, Xu Q. Does intramedullary canal irrigation reduce fat emboli? A randomized clinical trial with transesophageal echocardiography. J Arthroplasty. 2015; 30(3): 451-5. doi: 10.1016/j.arth.2014.10.006

82. Müller C, Frigg R, Pfister U. Effect of flexible drive diameter and reamer design on the increase of pressure in the medullary cavity during reaming. Injury. 1993; 24: S40-S7. doi: 10.1016/0020-1383(93)90006-r

83. Habashi NM, Andrews PL, Scalea TM. Therapeutic aspects of fat embolism syndrome. Injury. 2006; 37(Suppl 4): S68-73. doi: 10.1016/j.injury.2006.08.042

84. Binkowska AM, Michalak G, Slotwinski R. Current views on the mechanisms of immune responses to trauma and infection. Cent Eur J Immunol. 2015; 40(2): 206-16. doi: 10.5114/ceji.2015.52835

85. Butteriss DJ, Mahad D, Soh C, Walls T, Weir D, Birchall D. Reversible cytotoxic cerebral edema in cerebral fat embolism. AJNR Am J Neuroradiol. 2006; 27(3): 620-3.

86. Sie MY, Toh KW, Rajeev K. Cerebral fat embolism: an indication for ICP monitor? J Trauma. 2003; 55(6): 1185-6. doi: 10.1097/01.TA.0000100833.57027.1F

87. Georgopoulos D, Bouros D. Fat embolism syndrome: clinical examination is still the preferable diagnostic method. Chest. 2003; 123(4): 982-3. doi: 10.1378/chest.123.4.982

88. Bullock R, Chesnut RM, Clifton G, Ghajar J, Marion DW, Narayan RK, et al. Guidelines for the management of severe head injury. Brain Trauma Foundation. Eur J Emerg Med. 1996; 3(2): 109-27. 